\title{
(a) \\ Personalization of therapy and polypills
}

\section{Ruth Webster and Anthony Rodgers}

We thank Dr Brugts for his comments (Brugts, J. J. Optimizing treatment benefit: individualized therapy or the polypill? Nat. Rev. Cardiol. doi:10.1038/nrcardio.2013. $\underline{185-\mathrm{cl}})^{1}$ in response to our News \& Views commentary (Webster, R. \& Rodgers, A. Prevention: Coronary artery calcium and polypill therapy. Nat. Rev. Cardiol. 11, 7-8 [2014]). ${ }^{2}$ We would like to make three main points in reply. First, the debate has been framed as 'tailoring' versus 'no tailoring', which is perhaps not surprising given that polypills are fixed-dose combination medications. However, tailoring is possible in several ways while still allowing patients to benefit from the adherence improvements of polypills. Numerous types of polypill with different components will become available, many with variable doses of the individual component drugs. Additionally, tailoring can occur 'on top' of a polypill.

Second, the postulated variations in treatment effect by pharmacogenetic risk score are extreme, ranging from a large treatment benefit in patients with a risk score $<1$ to probable harm in patients with a risk score $\geq 3$. ${ }^{3}$ Replication of these data obtained from the EUROPA trial is required beyond the small additional subgroup of participants in the PROGRESS trial, which the investigators acknowledge. ${ }^{3}$ The predictive ability of this pharmacogenetic risk score might prove to be considerably lower than suggested in the initial analysis, although still clinically important.

Third, tailoring individual medications in the context of combination therapy has less effect than might be expected, and an important role of polypills is improving long-term adherence to recommended combination therapy. After an individual medication is tailored to a patient, changes to the overall cardiovascular risk reduction conferred by all medications will be less marked than changes to the risk reduction conferred by that individual medication. To take the example cited by Dr Brugts, if the angiotensin-converting-enzyme (ACE) inhibitor genetic score data were judged to be reliable, the main clinical implication would be replacing ACE-inhibitor therapy in the subgroup of patients with a risk score $>3$ with another blood-pressure-lowering agent. The differences in predicted risk reduction from ACE-inhibitor therapy according to genetic risk score (Table 1) are extreme (from a $42 \%$ risk reduction in those with a risk score of 1 to an increase in risk of $26 \%$ in those with a risk score of 3 , that is, a difference of 84 percentage points), but differences in overall cardiovascular risk reduction are much more modest (from a reduction of $70 \%$ in those with a risk score of 1 to a reduction of $36 \%$ in those with a risk score of 3 , that is,

Table 1 | Predicted relative risk reductions according to genetic risk score ${ }^{3}$

\begin{tabular}{|c|c|c|c|c|c|}
\hline \multirow[t]{2}{*}{ Polypill component } & \multirow{2}{*}{$\begin{array}{l}\text { Risk } \\
\text { score } 1 \\
\text { (\%) }\end{array}$} & \multirow{2}{*}{$\begin{array}{l}\text { Risk } \\
\text { score } 2 \\
\text { (\%) }\end{array}$} & \multicolumn{3}{|c|}{ Risk score 3 (\%) } \\
\hline & & & $\begin{array}{l}\text { ACEI } \\
\text { given }\end{array}$ & $\begin{array}{l}\text { ACEI } \\
\text { withheld }\end{array}$ & $\begin{array}{l}\text { ACEI } \\
\text { substituted }\end{array}$ \\
\hline ACEI* & 42 & 19 & -26 & 0 & 15 \\
\hline $\begin{array}{l}\text { Second blood-pressure-lowering } \\
\text { drug (e.g. } \beta \text {-blocker) }\end{array}$ & 15 & 15 & 15 & 15 & 15 \\
\hline Statin & 25 & 25 & 25 & 25 & 25 \\
\hline Aspirin & 20 & 20 & 20 & 20 & 20 \\
\hline $\begin{array}{l}\text { Overall relative risk reduction } \\
\text { with combination treatment }\end{array}$ & 70 & 59 & 36 & 49 & 57 \\
\hline
\end{tabular}

*ACEl effects are postulated on the basis of point estimates in the Brugts et al. paper. ${ }^{3}$ As noted in the original paper, these require validation and replication. ${ }^{3}$ Overall relative risks are estimated on the basis of data from clinical trials

indicating a lack of interactions on multiplicative scale..$^{8,9}$ Scores are assumed not to correlate with other treatment effects.

Abbreviation: ACEI, angiotensin-converting-enzyme inhibitor.

a difference of 34 percentage points). In the context of additional therapies (such as dual antiplatelet therapy or potent statin therapy), the marginal benefits on overall risk reduction from tailoring individual therapy would be even more modest. Furthermore, at a population level, the effect on the total number of events prevented would not be high, because only $27 \%$ of the population have a genetic risk score $\geq 3$. $^{3}$

Advances in tailoring treatment, such as the use of pharmacogenetic scores, might lead to improved blood-pressure control over time, although substantial barriers exist to implementing these strategies in everyday practice. Ensuring long-term adherence to combination therapy maximizes the likelihood of an acceptable overall cardiovascular risk reduction, helping to compensate for the inevitable, but usually undetectable, ${ }^{4,5}$ variations in a patient's response to individual drugs. 'Pharmacological autocompensation' is the technical term, but this phenomenon could just as easily be described as 'covering all your bases' or 'hedging your bets'. Although the potential to tailor individual medications to treat hypertension exists, only around half of patients with hypertension in high-income countries (and even fewer in low-income and middle-income countries) take any blood-pressure-lowering medication, and hypertension is controlled in only $\sim 20 \%$ of these patients. ${ }^{6}$ Ultimately, the most-important role for the polypill is to increase access and long-term adherence to combination therapy for the majority of people with cardiovascular disease globally, who receive few recommended medications or none at all. ${ }^{7}$

The George Institute for Global Health, Level 13, 321 Kent Street, Sydney, NSW 2000, Australia (R.W., A.R.).

Correspondence to: A.R. arodgers@georgeinstitute.org

\section{Competing interests}

The George Institute for Global Health, where the authors are employed, has secured a licence for two polypills that were used in clinical trials, after a decision by the manufacturer not to take the products to market because of regulatory issues. 


\section{CORRESPONDENCE}

1. Brugts, J. J. Optimizing treatment benefit: individualized therapy or the polypill? Nat. Rev. Cardiol. http://dx.doi.org/10.1038/nrcardio. 2013.185-c1.

2. Webster, R. \& Rodgers, A. Prevention: Coronary artery calcium and polypill therapy. Nat. Rev. Cardiol. 11, 7-8 (2014).

3. Brugts, J. J. et al. Genetic determinants of treatment benefit of the angiotensin-converting enzyme-inhibitor perindopril in patients with stable coronary artery disease. Eur. Heart J. 31 1854-1864 (2010).
4. Keenan, K., Hayen, A., Neal, B. C. \& Irwig, L. Long term monitoring in patients receiving treatment to lower blood pressure: analysis of data from placebo controlled randomised controlled trial. BMJ 338, b1492 (2009).

5. Glasziou, P., Irwig, L. \& Mant, D. Monitoring in chronic disease: a rational approach. BMJ 330 644-648 (2005).

6. Chow, C. K. et al. Prevalence, awareness, treatment and control of hypertension in rural and urban communities in high-, middle- and lowincome countries. JAMA 310, 959-968 (2013).
7. Yusuf, S. et al. Use of secondary prevention drugs for cardiovascular disease in the community in highincome, middle-income, and low-income countries (the PURE study): a prospective epidemiological survey. Lancet 378, 1231-1243 (2011).

8. Rodgers, A. et al. An international randomised placebo-controlled trial of a four-component combination pill ("polypill") in people with raised cardiovascular risk. PLoS ONE 6, e19857 (2011).

9. Wald, N. J. \& Law, M. R. A strategy to reduce cardiovascular disease by more than $80 \%$. BMJ 326, 1419 (2003). 